УДК 81'373.

ББК 81.411

\section{B.C. Савельев}

\section{ФУНКЦИИ ОБРАЩЕНИЯ В РАССКАЗЕ Ф. ИСКАНДЕРА "ХАРЛАМПО И ДЕСПИНА"}

На материале рассказа Ф. Искандера «Харлампо и Деспина» анализируется использование обращений. Устанавливаются их функции (апеллятивно-вокативная, фокусирующая, межличностная, иллокутивная, сегментирующая), роль в создании речевых портретов персонажей, особенности оформления (слогоделение, пунктуационные знаки) и авторского комментария, связанного с реализацией нарративной стратегии с прагматически мотивированным повествователем.

Ключевые слова: Ф. Искандер, «Харлампо и Деспина», функции обращения.

DOI 10.18522/1995-0640-2020-2-122-130

Савельев Виктор Сергеевич - канд. филол. наук, доцент Московского государственного университета имени М.В. Ломоносова

Тел.: 8-495-939-26-05

E-mail: alfertinbox@mail.ru

(C) Савельев В.С., 2020.
В произведении Фазиля Искандера «Харлампо и Деспина», издававшемся и издаваемом и как отдельный рассказ, и как глава романа «Сандро из Чегема», встречается художественный прием, использование которого делает этот текст уникальным, не похожим ни на один другой.

Рассказчик повествует об истории двух влюбленных - Харлампо и Деспины. Как это часто бывает у Искандера, одним из главных «двигателей» сюжета является диалог: в небольшом по объему тексте 1 обнаруживается 64 диалогических фрагмента, и почти в половине из них - в 29 - герои произносят обращения. Иногда в одном диалоге обращения звучат несколько раз: в общей сложности в тексте их насчитывается 40. Но не высокая частотность их использования обращает на себя внимание - вернее, не только она, - а то, как они используются.

Обращение представляет собой языковую единицу, которая употребляется в качестве высказывания в ряде функций ${ }^{2}$. Главной из них является апеллятивно-вокативная (обращение является первым речевым шагом инициальной реплики и используется для привлечения внимания собеседника и «вовлечения» его в диалог):

$<1>$ Тетушка Хрисула прекрасно знает, что Харлампо там, но почему-то никакого волнения не проявляет. <..>

- Хрисула, - говорил ктонибудь и многозначительно кивал в сторону кухни, - там Харлампо и Деспина?!

- A-a-a, - махала рукой тетушка Хрисула, - жених и невеста! [Искандер, 2003, с. 262]. 
Использование обращения в фокусирующей функции позволяет говорящему усилить «фокус внимания» собеседника при произнесении важного сообщения:

$<2>$ Медленно бледнея, Харлампо медленно встал с кушетки <...> сказал непреклонным голосом:

- Вот твой отец, Деспина! Другого отиа у тебя нет, Деспина! Филисе тон патеро су, Деспина! (Поцелуй своего отиа, Деспина!)

И Деспина вскочила, Деспина расплакалась, Деспина рассмеялась $и$ мгновенно преобразилась в прежнюю цветущую, веселую девушку (Искандер, 2003, с. 317) - Харлампо произносит постпозитивное обращение 3 раза, давая понять своей возлюбленной (да и всем, кто присутствует рядом), что его сообщения имеют особую важность.

Употребление диминутива в качестве обращения позволяет реализовать межличностную функцию (устанавливается определенный тип социальных отношений между коммуникантами):

$<3>$ Она подбежала к старому Хабугу и, наклонившись, нежно обняла его и поцеловала в обе щеки. <...>

- Теперь меня, Деспиночка! - крикнул Чунка по-русски [Искандер, 2003$, с. 317$]$ - ласковое обращение к собеседнику передает информацию об отношении к нему говорящего.

Наконец, обращение используется в качестве высказывания с определенной иллокутивной функцией (далее - ИФ):

$<4>$ - , nатера, - произносил он сквозь зубъ - несколько раз в день без всякого внешнего повода, и было ясно, что в душе его, никогда не затухая, бушует пламя обиды (Искандер, 2003, с. 250);

$<5>$ - 0 , nатера?! - произносил он иногда с гневным удивлением, подняв глаза к небу, и тогда можно было понять его так: «Отеи небесныци, разве это отеи?!» (Искандер, 2003, с. 250);

$<6>$ Обычно после әтого Харлампо озирался $и$, поймав глазами тетушку Хрисулу, через нее, как через передаточную станцию, отправлял отиу Деспины свой незатухающий, свой сумрачный укор.

- о, патера, - иногда при этом выклокатьввало из него (Искандер, 2003, с. 255).

Харлампо 3 раза взывает к Господу, и в каждом из случаев произносит обращение «О, патера», но делает это по-разному и с разными целями - об этом свидетельствуют комментарии рассказчика и пунктуация:

$<4>$ ИФ «обида» (рассказчик а) дает характеристику локутивному акту - произносил он сквозь зубы, б) определяет психологическое состояние Харлампо, выражением которого и является обращение - в душе его <...> бушует пламя обиды, в) «намекает» на интонацию, с которой произносилось обращение, при помощи запятой),

$<5>$ ИФ «негодование» (рассказчика) определяет психологическое состояние Харлампо - произносил <...> с гневным удивлением, б) описывает жест, сопровождающий локуцию - подняв глаза к небу, в) «расшифровывает» косвенный речевой акт, в качестве которого используется обращение, - тогда можно было понять его так: «Отеи, небесный, раз- 
ве это отец?!», г) «намекает» на интонацию, с которой произносилось обращение, при помощи вопросительного и восклицательного знаков), $<6>$ ИФ «укор» (рассказчик а) называет ИФ - свой сумрачный укор, б) дает характеристику локутивному акту - выклокатььвало из него, в) «намекает» на интонацию - аналогично $<4>$ ).

Использование обращений в указанных функциях не является чемто необычным и может быть обнаружено во множестве художественных произведений разного времени создания. Однако в «Харлампо и Деспина» есть один персонаж, речевой портрет которого уникален: Хрисула, тетушка Деспины, приставленная к ней в качестве девохранительницы, в 29 из 40 своих реплик произносит обращения, в 28 случаях адресованные Деспине, и чаще всего никакие другие слова ею не произносятся, так что речевой портрет персонажа по сути сводится к использованию им обращений.

Следует заметить, что, на первый взгляд, обращения к Деспине лишены смысла: Деспина должна понимать, что Хрисула обращается именно к ней, поскольку она говорит с ней по-гречески, а окружающие по-гречески не говорят ${ }^{3}$. Однако это не так. Как правило, реплики Хрисулы представляют собой бесконечные поучения, произносимые в тот момент, когда Деспина делает что-то, с точки зрения Хрисулы, неправильное. В этот момент Хрисула стремится пресечь действие Деспины, и, с одной стороны, ей необходимо привлечь внимание племянницы, а с другой - обратить внимание на важность сообщения (апеллятивно-вокативная и фокусирующая функции). Использование обращения является действенным средством достичь этих целей.

Все реплики Хрисулы можно разделить на 4 группы:

1. В 5 случаях помимо обращения Хрисула произносит и другие слова:

$<7>$ Бывало, по вечерам в кухне или на веранде собирались молодые чегемиы, и Деспина с удовольствием с ними болтала по-русски или потурецки, порой безудержно хохоча шуткам чегемских парней, на что неизменно получала замечание от тетушки Хрисуль.

- Кондрепесо, Деспина! (Не стьдно, Деспина!) - говорила она и чтото добавляла по-гречески, судя по движению ее губ, показывала предель приличия <..> (Искандер, 2003, с. 254) - фразу Кондрепесо, Деспина! Хрисула произносит в 3 диалогах; употребление обращения в постпозиции связано с реализацией ИФ: обращение видоизменяет исходную ИФ высказывания «замечание», повышая уровень его «прескриптивности»;

$<8>$ И эта взаимная воркотня, с равномерными паузами, вздохами тетушки Хрисуль и повторами, как-то сама собой делалась понятной, словно они говорили по-русски или по-абхазски.

- Хрисула - глупышка, Хрисула немножко перебрала...

- Деспина, прости свою старушку...

- Хрисула глупенькая, Сула немножко перебрала... (Искандер, 2003, с. 258) - препозитивное обращение используется в сегментирующей 
функции, маркируя переход к новому коммуникативному эпизоду (далее - КЭ) (информативный эпизод сменяется прескриптивным: Хрисула просит простить ее).

Общим для $<7>$ и $<8>$ является то, что рассказчик обращает внимание на то, что коммуниканты общаются на греческом языке: будучи прагматически мотивированным повествователем, он соблюдает «правила игры» и рассказывает о своем незнании того, о чем говорят его персонажи, только лишь пытаясь догадаться о смысле разговора;

$<9>$ Тетушка Хрисула сказала, что, когда они в последний раз уходили с Деспиной из Большого Дома в Анастасовку, она по дороге съела почти полкорзины грецких орехов и никакой ореховой дурью не заболела.

- Правда, Деспина? - обратилась она к племяннице, но отозвался Чунка (Искандер, 2003, с. 315) - как и в <8>, обращение в <9> маркирует начало нового КЭ, однако в этом случае происходит смена адресата, а потому обращение используется и для того, чтобы обратить на себя внимание нового собеседника (апеллятивно-вокативная функция);

2. В 6 случаях рассказчик не приводит никаких иных слов Хрисулы, но сообщает, что она произносила что-то помимо обращения:

$<10>$ Стоило, скажем, Деспине погладить большую кавказскую овчарку, забежавшую на веранду, как тетушка Хрисула < .. > останавливала ее.

- Деспина, - говорила она и что-то поясняла. Судя по тому, что она при этом показывала на кошку, мирно дремавшую на балюстраде веранды, можно было догадаться, что «аристократико корице» <...> не должна забавляться с пастушеской овчаркой, но при этом смело может погладить кошку или даже взять ее на руки (Искандер, 2003, с. 265);

$<11>$ Девушка < ... > достала большую лиловую сливу и только хотела надкусить ее, как тетушка Хрисула выхватила у нее плод.

- Деспина! - воскликнула она и, быстро протирая сливу о подол своего платья, стала ей что-то объяснять.

По-видимому, речь шла о том, что девушка ее круга, прежде чем надкусить сливу, обязательно должна стереть с нее пыльцу (Искандер, 2003, c. 266);

$<12>$ - Деспина! - строго окликнула она ее, когда ветка, на которой стояла девушка, оказалась выше, чем ветка, на которой стоял Чунка. При этом она что-то залопотала, для наглядности оглаживая собственное платье и явно напоминая ей, что «аристократико корице», оказавшись на одном дереве с чужим мужчиной, не должна подьматься на такую высоту (Искандер, 2003, с. 269);

$<13>$ Когда тетушка Хрисула пришла в себя, Деспина уже отправляла в рот сладостную мякоть плода.

(а) - Деспина! - истошно закричала тетушка Хрисула и быстробыстро залопотала, по-видимому, объясняя ей, что аристократическая девушка, оказавшись с чужим мужчиной на одном дереве, не может принимать от него плодов этого дерева, тем более плод, оскверненный его поцелуем. $<\ldots>$ 
Деспина ей что-то отвечала, и, судя по движению ее рук, она показывала, что съела инжир, очистив его от шкурки и тем самым нейтрализовав действие оскверняющего поцелуя.

(б) - Деспина! - в отчаянии крикнула тетушка Хрисула и, выбросив обе руки в стороны, что-то пролопотала, по-видимому, означающее: зачем вообще надо было есть этот инжир?!

Дожевывая инжир, Деспина что-то ответила тетушке Хрисуле, и, судя по движению ее рук и взгляду на ветку, где стоял Чунка, она сказала, что инжир был брошен без ее одобрения и ей ничего не оставалось, как поймать его и съесть.

(в) - Деспина! - крикнула тетушка Хрисула <... После этого она снова залопотала, беспрерывным движением рук поясняя свои слова, так что легко было понять, что она имела в виду (Искандер, 2003, с. 272, 273).

Комментарий рассказчика во всех приведенных фрагментах имеет одну и ту же структуру: он 1) упоминает локутивный акт, в большинстве случаев указывая на невозможность понять сказанное (используется квантор что-то), 2) описывает жест Хрисулы, сопровождающий говорение, 3) высказывает догадку о том, что означают слова и жесты Хрисулы, подчеркивая, что это именно догадка (используется показатель персуазивности по-видимому).

Таким образом, как и в $<7>$ и $<8>$, в $<10>-<13>$ реализуется нарративная стратегия с прагматически мотивированным повествователем, постоянно напоминающим читателю об ограниченности своего знания;

3. В 2 случаях рассказчик упоминает жест Хрисулы, позволяющий ей передать Деспине необходимую информацию, не произнося при этом слов:

$<14>$ Поедая инжиры, тетушка Хрисула беспрерывно тараторила.

- Деспина! - кричала она и, воздев руку, показывала девушке на спелый инжир (Искандер, 2003, с. 269) - реплика Хрисулы является прескриптивной: обращение используется в апеллятивно-вокативной функции, а жест позволяет понять, что Деспина должна сорвать инжир;

$<15>$ - Деспина! - сокрушенно крикнула ей в ответ тетушка Хрисула, пораженная ее наивностью $u<\ldots>$ жестами показала, с какой легкостью при желании Чунка может перескочить со своей ветки на ее ветку (Искандер, 2003, с. 270) - прескрипция Хрисулы передается обращением (Деспина должна перестать делать то, что она делает), а жест выполняет аргументативную функцию, поясняя прескрипцию;

4. Чаще всего - в 15 случаях - Хрисула произносит обращение, не сопровождая его ни словами, ни жестами, и данные примеры наиболее показательны. С одной стороны, автор использует этот прием, создавая художественное пространство своего текста: сведение реплики Хрисулы к обращению позволяет ему прокомментировать происходящее в своей обычной ироничной манере. С другой стороны, эти реплики иллюстрируют потенциал использования обращения как языковой единицы.

А. В 4 случаях обращение используется в апеллятивно-вокативной функции в ситуации, когда Хрисула не видит свою племянницу и 
выкликает ее имя, но не для того, чтобы начать с ней разговор, а для того, чтобы установить аудиальный или визуальный контакт - Деспина должна откликнуться или подойти к ней:

<16> Все произошло в несколько секунд, если они и сговорились, то мы внизу этого не заметили.

- Деспина! - в ужасе крикнула тетушка Хрисула.

Никакого ответа.

- Деспина! - И опять безмолвие (Искандер, 2003, с. 274);

$<17>$ Как ни отвлекали тетушку Хрисулу, через некоторое время она забеспокоилась, вынла во двор и стала кричать:

\section{- Деспина! Деспина!}

Деспина отозвалась (Искандер, 2003, с. 263).

В <17> обращает на себя внимание, что Хрисула зовет Деспину дважды: редупликация при использовании обращения в пределах одной реплики встречается в тексте три раза, причем в одном случае она затрагивает фразу Кондрепесо, Деспина! (<18> Тетушка Хрисула всплеснула руками и побежала им навстречу. - Кондрепесо, Деспина! Кондрепесо, Деспина! - кричала она, указывая на Харлампо (Искандер, 2003, с. 264)).

Стремление Хрисулы к постоянному контролю за действиями Деспины наиболее ярко иллюстрирует следующий пример:

$<19>$ По уверению тех же сестрич, тетушка Хрисула за ночь несколько раз, не просыпаясь, произносила: «Деспина!» - и опять же, не просыпаясь, подергивала руку, чтобы почувствовать тяжесть головы Деспины (Искандер, 2003, с. 263) - даже во сне Хрисула проверяет, где находится ее племянница.

Б. Использование обращения в $<20>$, в целом похожее на $<16>$ и $<17>$ (стремление к установлению контакта), отличается в деталях:

$<20>$ Но если тетушка Хрисула, заметив отсутствие Деспинь, вспоминала, что она, скажем, увлекиись разговором, уже минут десять как выпустила ее из виду <... > она забывала о всякой маскировке.

- Деспина! - кричала она и вскакивала, словно пытаясь голосом еще до того, как добежала до кухни, удержать ее от гибельного шага (Искандер, 2003, с. 262) - рассказчик указывает, что реплику Хрисулы следует воспринимать как прескрипцию (ИФ «предостережение»: пытаясь голосом еще до того, как добежала до кухни, удержать ее от гибельного шага); таким образом, обращение в $<19>$ обладает ИФ, не являясь исключительно фатическим актом.

В. Совмещение апеллятивно-вокативной и иллокутивной функций и, следовательно, использование обращения как полифункционального высказывания наблюдается также и в тех случаях, когда Деспина находится в поле зрения Хрисулы и обращение служит прескрипцией (8 реплик):

$<21>$ Если Деспина, бывало, забывшись, на минуту выходила на солнце, не сдвинув косынку на лицо, тетушка Хрисула тут же ее окликала:

- Деспина! 
И Деспина привыюным, ловким движением стягивала косынку на лицо (Искандер, 2003, с. 252);

$<22>$ Умьвшись, Харлампо разгибался и протягивал ладонь к полотениу, висящему на плече у девушки <...>

- Деспина, - все-таки считала тетушка Хрисула не лишним напомнить о приближающейся опасности (Искандер, 2003, с. 257);

$<23>$ И Деспина, взглянув на Чунку, весело расхохоталась, и тетушка Хрисула тоже мгновенно преобразилась в прежнюю тетушку Хрисулу и совсем прежним голосом предупредила племяннич:

\section{- Дес-пи-на!}

Преображение ее было столь удивительным, что все рассмеялись (Искандер, 2003, с. 317);

$<24>$ Несколько минут длилось горькое прощание влюбленных. <..>

- Деспина, - вмешивалась в этот дуэт тетушка Хрисула, сама рассттоенная и стараясь успокоить племяннииу (Искандер, 2003, с. 301, 302).

Прескрипции Хрисулы можно разделить на две группы: в одних случаях она просит ее что-то сделать (ИФ «приказ»: $<21>)$, в других чего-то НЕ делать (ИФ «предостережение»: <22>, <23>). Особо следует выделить фрагмент $<24>$, в котором Хрисула стремится пресечь диалог Деспины и Харлампо и в то же время утешить свою племянницу.

$\mathrm{B}<23>$ обращает на себя внимание способ графического оформления высказывания: автор осуществляет слогоделение слова Дес-пи-на, а также использует восклицательный знак, что позволяет ему передать информацию о локутивных особенностях этого речевого акта.

Г. В двух случаях функциональная нагруженность обращения оказывается еще большей, чем в $<20>-<24>$ :

$<25>$ Иногда, даже если Деспина и не хохотала, а просто слишком оживленно разговаривала с каким-нибудь из чегемских парней, тетушка Хрисула снова делала ей замечание.

- Деспина! - предупреждала ее тетушка Хрисула и, обращаясь к тете Нуце, говорила, ито Деспина здесь, в Чегеме, совсем отбилась от рук, ошалев от встречи с Харлампо (Искандер, 2003, с. 254) - прескриптивное предупреждение Хрисулы (Деспина! = «Перестань так себя вести!») одновременно является осуждающим оценочным суждением (Деспина! = «Ты ведешь себя неприлично»);

$<26>$ Минуты через две или три из густой листвы раздался смех Деспины и хохот Чунки.

- Деспина! - крикнула тетушка Хрисула с надрывным упреком и все-таки радуясь, ито она, по крайней мере, жива (Искандер, 2003, с. $275)$ - упрек Хрисулы содержит не только оценку, но и прескрипцию.

Возможность восприятия $<25>$ и $<26>$ как оценочных суждений связана с тем, что такую характеристику дает им сам рассказчик $(<25>$ : делала ей замечание; <26>: с надрывным упреком).

Во всех случаях использования обращения, не сопровождаемого словами и/или жестами (см. $<16>,<17>,<19>-<26>$ ), обнаруживает- 
ся общий принцип его функционирования: когда Хрисула обращается к племяннице, та должна сама догадаться о том, что имеет в виду ее тетя. Иначе говоря, она должна вывести импликатуру, оценив ситуацию, в которой произносится реплика Хрисулы, чаще всего отталкиваясь от пресуппозиции «то, что я делаю сейчас, неправильно».

Квинтэссенцией использования обращений в «Харлампо и Деспина» является диалог, часть которого была приведена в $<24>$ :

$<27>$ Несколько минут длилось горькое прощание влюбленньх.

- (1) Харлампо, - говорила Деспина, и ее синие глазки наполнялись слезами.

- (2) Деспина, - глухо, с грозной тоской выдыхал Харлампо, и скуль его начинали дьишать желваками.

- (3) Харлампо!

- (4) Деспина! - глухо, сдержанно, с такой внутренней силой говорил Харлампо <...>

- (5) Деспина, - вмешивалась в этот дуэт тетушка Хрисула, сама расстроенная и стараясь успокоить племянницу $<\ldots>$

- (6) Харлампо, - успокаивала тетя Нуца своего пастуха и поглаживала его по широкой спине (Искандер, 2003, с. 301, 302).

Диалог $<27>$ состоит из 3 КЭ, в них участвуют 4 коммуниканта.

КЭ1, включающий реплики (1)-(4), является фатическим (коммуниканты - Деспина и Харлампо); КЭ2, включающий реплику (5), является прескриптивным (коммуниканты - Хрисула и Деспина); КЭ2, включающий реплику (6), является прескриптивным (коммуниканты - Нуца и Харлампо).

Все реплики диалога представляют собой обращения. При этом в КЭ1 реплики (2) и (4) являются реактивными, в отличие от всех остальных случаев: в норме обращениям свойственно использование в качестве инициальных реплик, маркирующих начало нового КЭ.

Таким образом, анализ текста позволил установить следующее: 1) обращению свойственны разные функции (апеллятивно-вокативная, фокусирующая, межличностная, иллокутивная, сегментирующая), в ряде случаев они совмещаются (обращение используется как полифункциональное высказывание); 2) на функциональную нагрузку обращения оказывает влияние то, произносятся ли помимо обращения другие слова и, если произносятся, то в какой части реплики находится обращение; сопровождается ли речь говорящего жестами; находится ли адресат в поле зрения говорящего; 3) определение функций обращения опирается на комментарий рассказчика; 4) введение обращения в текст связано с использованием ряда графических средств (слогоделение, пунктуационные знаки); 5) автор использует обращение как средство создания речевого портрета персонажей; ограничение их речи произнесением обращения позволяет комментировать происходящее с позиций прагматически мотивированного повествователя. 


\section{Примечания} 2014].

176 страниц в издании [Искандер, 2003], 30 страниц в издании [Искандер,

${ }^{2}$ О функциях обращений см. [Савельев, 2018].

${ }^{3}$ Исключением служат диалоги, происходящие в присутствии Харлампо.

${ }^{4}$ Интересно, что в разных изданиях графическое оформление фрагмента $<12>$ различается: в [Искандер, 2003, с. 269] слогоделение отсутствует, зато оно обнаруживается в издании [Искандер, 2014, с. 393].

\section{Литература}

Искандер Ф. Сандро из Чегема // Искандер Ф. Собр. соч.: в 10 т. Т. 2. М.: Время, 2003.

Искандер Ф. Сандро из Чегема. М.: Эксмо, 2014.

Савельев В.С. Функции обращений в прямой речи героев «Повести временных лет» (статья 2) // Вестн. Моск. ун-та. Серия 9. Филология. 2018. № 2. C. 35-60.

\section{References}

Iskander F. Sandro iz Chegema. Sobranie sochinenii v 10 tomakh. T. 2. M., Vremya, 2003. (In Russian).

Iskander F. Sandro iz Chegema. M., Eksmo, 2014. (In Russian).

Savel'ev V.S. Funktsii obrashchenii v pryamoi rechi geroev «Povesti vremennykh let» (stat'ya 2). Vestn. Mosk. un-ta. Seriya 9. Filologiya, 2018, no. 2. pp. 35-60. (In Russian).

Victor S. Savelyev (Moscow, Russian Federation)

Functions of the Addresses in the Story by F. Iskander «Harlampo and Despina»

The article is devoted to the analysis of the use of addresses in the story of F. Iskander «Harlampo and Despina». We define their functions (appealvocative, focusing, interpersonal, illocutional, segmentation), role in creating speech portraits of characters, graphic design (syllabication, punctuation marks) and author's comment of their use related to the implementation of narrative strategy with a pragmatically motivated narrator.

Key words: F. Iskander, «Harlampo and Despina», functions of addresses.

Victor S. Savelyev - Ph. D. of Philology, Associate Professor at the Lomonosov Moscow State University. Phone: 8-495-939-26-05; e-mail: alfertinbox@mail.ru 